J Venom Anim Toxins incl Trop Dis, 2019 25: e144118

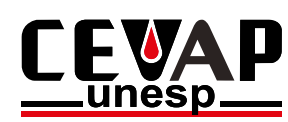

The Journal of Venomous Animals and

Toxins including Tropical Diseases

ISSN 1678-9199

Journal homepage www.jvat.org

\title{
Nanoparticulate drug delivery systems for the treatment of neglected tropical protozoan diseases
}

\author{
Greta Volpedo ${ }^{1,2}$, Lourena Costa ${ }^{1,3}$, Nathan Ryan ${ }^{1}$, Gregory Halsey ${ }^{1}$, Abhay Satoskar ${ }^{1,2}$, Steve Oghumu ${ }^{1, *} \mathbb{D}$ \\ ${ }^{1}$ Ohio State University Wexner Medical Center, Department of Pathology, Columbus, OH, 43210, USA. \\ ${ }^{2}$ Ohio State University, Department of Microbiology, Columbus, $\mathrm{OH}, 43210$, USA. \\ ${ }^{3}$ Universidade Federal de Minas Gerais, Faculdade de Medicina, Departamento de Infectologia e Medicina Tropical, Belo Horizonte, MG, Brasil.
}

\section{Article Info \\ Keywords:}

Leishmaniasis

Chagas

Trypanosomiasis

Nanoparticles

Liposomes

Nanotubes

Nanodiscs

Micelles

\begin{abstract}
Neglected Tropical Diseases (NTDs) comprise of a group of seventeen infectious conditions endemic in many developing countries. Among these diseases are three of protozoan origin, namely leishmaniasis, Chagas disease, and African trypanosomiasis, caused by the parasites Leishmania spp., Trypanosoma cruzi, and Trypanosoma brucei respectively. These diseases have their own unique challenges which are associated with the development of effective prevention and treatment methods. Collectively, these parasitic diseases cause more deaths worldwide than all other NTDs combined. Moreover, many current therapies for these diseases are limited in their efficacy, possessing harmful or potentially fatal side effects at therapeutic doses. It is therefore imperative that new treatment strategies for these parasitic diseases are developed. Nanoparticulate drug delivery systems have emerged as a promising area of research in the therapy and prevention of NTDs. These delivery systems provide novel mechanisms for targeted drug delivery within the host, maximizing therapeutic effects while minimizing systemic side effects. Currently approved drugs may also be repackaged using these delivery systems, allowing for their potential use in NTDs of protozoan origin. Current research on these novel delivery systems has provided insight into possible indications, with evidence demonstrating their improved ability to specifically target pathogens, penetrate barriers within the host, and reduce toxicity with lower dose regimens. In this review, we will examine current research on these delivery systems, focusing on applications in the treatment of leishmaniasis, Chagas disease, and African trypanosomiasis. Nanoparticulate systems present a unique therapeutic alternative through the repositioning of existing medications and directed drug delivery.
\end{abstract}

\footnotetext{
* Correspondence: 


\section{Background Neglected tropical diseases}

Neglected Tropical Diseases (NTDs) represent a group of seventeen diseases caused by viruses, bacteria and parasites. NTDs are responsible for a substantial portion of the global health burden and affect more than a hundred nations, primarily developing countries and areas where communities live in poor sanitary and hygienic conditions [1] (http://www. who.int/neglected_diseases/diseases/en/; https://www.cdc. gov/globalhealth/ntd/index.html). The health burden caused by NTDs is often accompanied by a financial challenge, as developing effective public health approaches to control the disease costs billions of dollars per year [2]. Furthermore, these diseases can cause long-lasting effects that can prevent infected individuals from earning a living, impacting the already precarious socio-economic situation of many communities [2-4]. Despite the efforts of the international community to control these diseases, NTDs are still a long way from being completely eradicated. Some of the issues related to this are tied to the fact that NTD endemic areas often have unstable political situations and can be subjected to military unrest [5]. For example, social instability and turmoil following the independence conflicts in many African countries between the 1980s and 1990s, led to a rapid resurgence of Trypanosoma brucei infections [3]. In addition to this, NTD endemic areas are often geographically restricted and therefore do not attract the attention they deserve by the global community [5]. Out of the 17 official NTDs, this review will focus on the three protozoan diseases leishmaniasis, Human African Trypanosomiasis (HAT) and Chagas disease, as these three conditions are single handedly responsible for the highest number of deaths among all NTDs [6].

\section{Leishmaniasis}

\section{a. Epidemiology}

Leishmaniasis is caused by Leishmania protozoan parasites and is transmitted by female Phlebotomine sandflies. Leishmaniasis affects over 10 million people in more than 90 tropical and sub-tropical countries in the new and old world $[2,7]$. Human infection is mediated by about 21 species of Leishmania parasites and can take three different forms [8]. The most life-threatening form is visceral leishmaniasis (VL) with an estimated incidence of about 400,000 cases per year and a mortality rate of up to $95 \%$ if left untreated and up to $10 \%$ even when treated [9]. VL can be associated with an acute or chronic infection characterized by fever, anemia and swelling of the spleen and liver $[7,9,10]$. The most widespread form is cutaneous leishmaniasis (CL), with an incidence of about 2 million cases every year. Although the risks for fatality are very low with this infection, CL leads to large lesions that can result in disfiguring scars after healing [8]. Lastly, muco-cutaneous leishmaniasis (MCL) affects the mucosal tissue of mouth, nose and throat and can lead to the partial or total disintegration of these tissues $[7,8]$. CL and MCL can cause disabilities and their clear manifestations are often a reason for stigma and prejudice in affected communities [2, 8].

\section{b. Immunity}

An area of active research is the study of host immunology against protozoan NTDs. Understanding the immunological processes at play during parasitic infection is crucial for the development of new therapeutics and prophylactic treatments [11]. In general, protective immunity against leishmaniasis is associated with a Th1 immune response. Th1 mediated cytokines such as interleukin (IL) 12, tumor necrosis factor alpha (TNF- $\alpha$ ) and interferon gamma (IFN- $\gamma$ ) have been shown to be critical for the control of this infection [8]. Macrophage activation by Th1 cytokines such as IFN- $\gamma$, elicits the production of nitric oxide (NO), important for parasite killing [8, 12]. In leishmaniasis, a Th2 immune response characterized by IL-10 production is often associated with disease susceptibility [13]. Along with Th2, B cell responses are also associated with susceptibility [14].

\section{c. Prevention \& Treatment}

For many years there has been considerable effort to find a candidate prophylactic vaccine for the protozoan NTDs. Some promising candidates for leishmaniasis include live attenuated vaccines [15-18], protein fraction vaccines $[15,19]$, phage therapy [20, 21], DNA vaccines [15, 22-24], chimeric vaccines [15], etc. Low market profitability, failure to confer a long lasting immunity, difference in pathogenic dynamics amongst Leishmania species as well as adjuvant suitability remain important challenges in the development of an effective Leishmania vaccine [15].

Treatment of these three protozoan NTDs is often challenging and there are currently only a handful of therapeutics available. Pentavalent antimonials have been the golden standard for the treatment of leishmaniasis for more than half a century. Since then, more drugs like amphotericin $\mathrm{B}(\mathrm{AmB})$, paromomycin $(\mathrm{PM})$, pentamidine, miltefosine, imiquimod and azoles have been approved [7]. These compounds are sometimes also used in combination with one another to increase efficacy and reduce the side effects [7]. These drugs have been associated with hypoglycemia, nephrotoxicity, pancreatitis, cardiopathy, hypotension and hepatotoxicity [25-27]. Increasing parasite drug resistance has also become a serious concern [26, 28-30].

\section{Chagas disease}

\section{a. Epidemiology}

Chagas disease is caused by the blood protozoan parasite Trypanosoma cruzi and is transmitted by contact with feces of infected triatomine bugs (kissing bugs) [31-33]. Chagas disease is prevalent in Central and South America, affecting about 8 million people and causing around 20,000 deaths each year (CDC Website) $[34,35]$. It is estimated that $25 \%$ of the population of Latin America is at risk for infection [34] and that 300,000 infected people currently live in the US [36, 37]. Just like leishmaniasis, Chagas disease is mainly a threat to those living in poor sanitation and in contact with insect vectors and 
reservoirs [37]. In the acute phase of the disease, lasting 4 to 8 weeks, patients usually manifest mild or no symptoms [38, 39]. After this initial phase, 20 to $30 \%$ of patients progress to a chronic infection [37]. This phase is characterized by cardiac, digestive and/or neurological pathologies that can lead to systemic and pulmonary embolisms and in the most severe cases, sudden death $[37,39]$.

\section{b. Immunity}

Similar to leishmaniasis, resistance to Chagas disease is mediated by a Th1-polarized immune response, which in turn activates innate immune cells $[11,16]$. Along with Th1 immunity, CD8+ and Th17-mediated responses are characteristic of protection against Chagas disease [40,41]. Differently from leishmaniasis, in Chagas disease, a balance between a pro and anti-inflammatory response seems necessary once the infection moves onto the chronic stage, the former to limit parasitic replication and spread of the infection, the latter to control and repair tissue damage $[39,42]$.

\section{c. Prevention \& Treatment}

There has been considerable effort for the development of a vaccine against Chagas disease. Killed and attenuated vaccines as well as cell fraction, purified protein, recombinant protein and DNA vaccines have been tested [43]. Current studies have found evidence suggesting a role for CD8+ T cells as vaccine effectors [44]. Although these strategies remain feasible, there are still some challenges to overcome. For instance, the use of protein vaccines, both purified and recombinant, are costly and time consuming. Additionally, DNA vaccines often need to be co-administered with immunostimulators to enhance their efficacy [43].

There are currently only two treatments available for Chagas disease: nifurtimox and benznidazole (BZN); these drugs frequently present adverse dermatological effects and can cause fever or lymphadenopathy [45]. Gastrointestinal disturbances such as anorexia, weight loss, nausea, vomiting, and abdominal discomfort are also common [45]. Associated neurotoxicity can cause irritability, insomnia, disorientation, and infrequently induces tremors [45]. More serious but less common adverse effects include paresthesia, polyneuropathy, and peripheral neuritis [45].

\section{Human African Trypanosomiasis}

\section{a. Epidemiology}

Human African trypanosomiasis (HAT), better known as "sleeping sickness", is caused by protozoan parasites of the species Trypanosoma brucei and is transmitted by the tsetse fly, found in sub-Saharan Africa [46, 47]. HAT can present itself in two different forms, depending on the subspecies of infective parasites. Trypanosoma brucei gambiense is responsible for the chronic form of the disease and accounts for $97 \%$ of reported cases in more than 20 countries [3, 46, 47]. On the other hand, Trypanosoma brucei rhodesiense is present in 13 countries and causes acute infections that can rapidly progress to affect the nervous system $[3,46,47]$. The first stage of HAT infection is the hemo-lymphatic stage in which the parasites replicate in the blood and lymph $[3,46,47]$. This primary phase is characterized by fever, headaches, and joint pains. Following this early stage, the parasites may cross the blood brain barrier and infect the central nervous system. This infection is referred to as the meningo-encephalic stage and is accompanied by neurological symptoms like confusion, behavioral changes, impaired coordination and sleep cycle disturbances [3, 46, 47]. When left untreated this disease can lead to coma and ultimately death by multiple organ failure [3].

\section{b. Immunity}

Pro-inflammatory innate and adaptive responses analogous to those observed in leishmaniasis and Chagas disease, are also crucial for the control of T. brucei infection [19-21]. While an early Th1 response is important for resistance, the development of a late Th2 response can mediate tissue repair and is therefore beneficial in HAT patients $[39,42]$. B cells also play an important role against T. brucei, as they release antibodies responsible for phagocytosis as well as classical pathway-mediated complement lysis [42, 48].

\section{c. Prevention \& Treatment}

Vaccine development to prevent T. brucei infection has also been accompanied by many challenges. A variable surface glycoprotein (VSG) coat continues to be the largest hurdle, preventing the development of any sort of prophylactic for HAT. Because of their clear role in pathogenesis, conserved regions in VSGs have been identified as potential antigenic vaccine targets [49], although these proteins might be more diverse than originally anticipated due to phenotypical clonal plasticity, making it difficult to identify widely "conserved" regions [49].

The current treatments for HAT are comprised of distinct and specific types of drugs for each of the two stages of $T$. brucei infection [50]. T. brucei acute infection can be treated by pentamidine or suramin, depending on the species, while the chronic phase can be controlled with melarsoprol or eflornithine plus nifurtimox [47]. These drugs can present serious side effects; for example, pentamidine treatment can lead to metabolism imbalance, cardiac and digestive problems while suramin can cause renal, neurological, epithelial, and bone marrow toxicity [47]. T. brucei treatments were developed nearly 50 years ago, are painful and can cause harmful side effects that may require hospitalization or cause death [47].

Because of the desperate need to find new prophylactic and therapeutic compounds to control these three protozoan NTDs, a considerable effort has been made to develop new potential therapeutics as well as screening for new drug targets. Due to the high cost and long timeline associated with novel drug development, it is often preferable to invest in drugs already used and approved. An approach is to change the formulation or delivery system of a drug and use it for the same disease it 
was originally developed for. The use of novel delivery systems can result in increased efficiency and reduced toxicity and side effects. Additionally, absorption of drugs with low solubility in water can be improved by encapsulating these compounds in lipid systems. This review will focus on lipid, polymeric and metallic/inorganic drug delivery methods for the treatment of leishmaniasis, HAT and Chagas disease. Our objective is to provide an overview of the different nanoparticulate delivery systems available for compounds that have been tested and shown to be effective for the treatment of the three protozoan NTD's.

\section{Nanoparticle drug delivery systems}

Recently, several research groups have incorporated existing therapeutics into nanoparticulate systems. While there are no internationally agreed definitions for nanoparticles, the Publicly Available Specification (PAS71), a document developed in the United Kingdom, describes a nanoparticle as a body having one or more dimensions of the order of $100 \mathrm{~nm}$ or less. Nanoparticulate systems currently in use involve, but are not limited to, lipid systems and polymeric/metallic constructions (Figure 1) [51]. There are several methods of action used by these nanoparticulate systems to specifically target tissues or cells. One of these mechanisms is through direct binding to particular cell surface receptors that may be overexpressed on the desired target [52]. Nanoparticles may also diffuse to tissues through passive permeability. Increased permeability of certain tissues due to higher metabolism rates can allow for the accumulation of nanoparticles, enhancing bioavailability [52]. Here, we briefly review the use of nanoparticulate systems in the treatment of tropical parasitic conditions (Figure 1).

\section{Lipid systems}

Amongst the nanoparticulate systems, the lipid particles are the simplest to produce on a large scale. They usually have a biocompatible profile, as their composition presents similarity to plasma membrane lipids and cholesterol of human beings and other vertebrate animals. Lipid nanoparticles are biodegradable in the environment and have low toxicity, especially when compared to polymeric particles $[53,54]$.

Lipid nanoparticles are administered through different routes notably: topical, ocular, oral, pulmonary, parenteral and cerebral. The topical route presents some limitations such as the difficulty of penetration in the skin / dermis, which depends on several factors such as lipophilicity, hydration and thickness of the epidermis. Ocular administration is a good option but, due to the complexity of the eye, the bioavailability of the drug is inconsistent. The particles must be able to overcome several barriers such as the mucosa, the corneal and conjunctival epithelium, and the ocular drainage. The oral route is one of the most used, due to simplicity of administration and good acceptability. However, the first-pass (hepatic) metabolism can greatly reduce the bioavailability of the drug. The pulmonary route is newly tested and is extremely interesting because it is noninvasive and the same time has good systemic bioavailability and presents low adverse effect. Lipid nanoparticles such as solid lipid nanoparticles (SLNs) and nanostructured lipid carrier (NLCs) can maintain high and constant levels of drugs in the blood (constant plasma levels). For the parenteral route, many studies use intravenous, intramuscular, subcutaneous and direct administration applied to specific organs. Cerebral administration has the potential to overcome the blood-brain barrier and maintain optimal

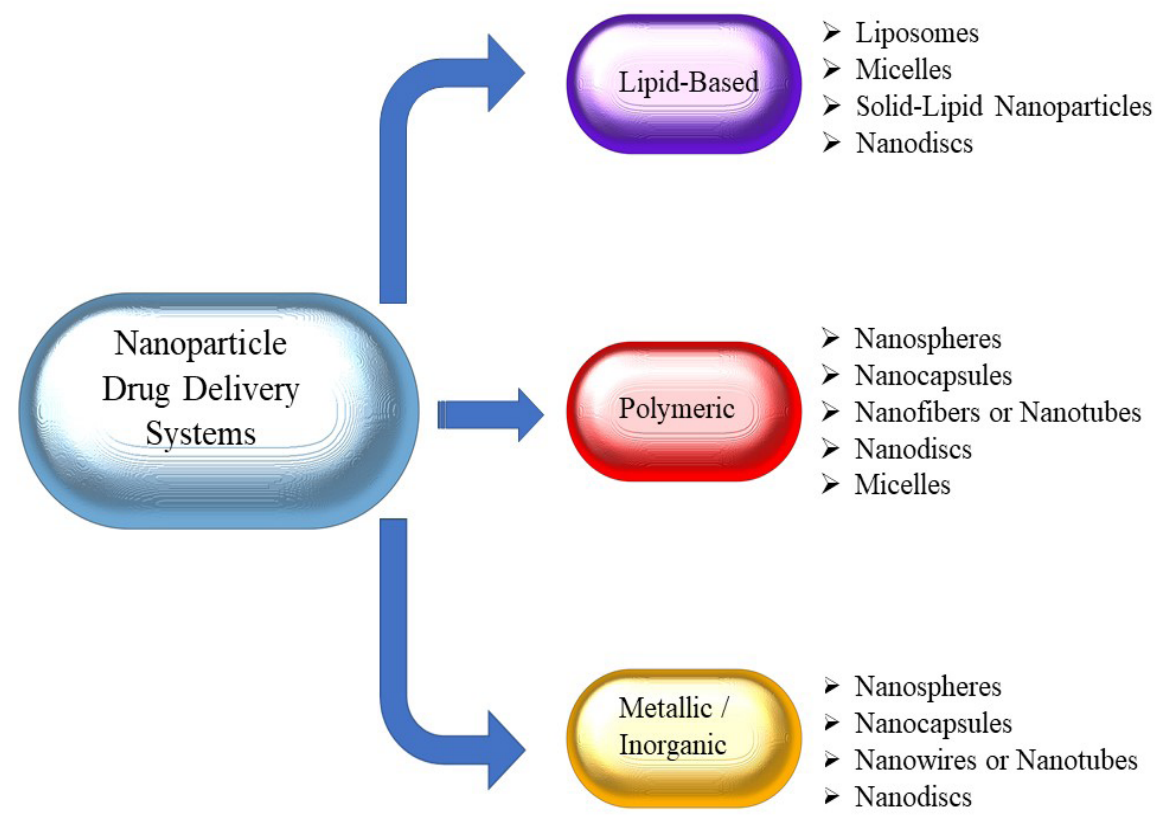

Figure 1 Overview of the relationship between nanoparticulate systems, divided by their structural organization. 
levels of drug delivery in the cerebral capillaries. For this route, it is necessary that the particle be very small on the order of micrometers or less than $100 \mathrm{~nm}[53,55]$.

The solubility of nanoparticles is inversely proportional to their size. For instance, solubility can be increased by reducing the diameter of a particle from micro to nanometers. Nanoparticles vary in size (<100 nm); for instance, SLNs have submicron $(<1000 \mathrm{~nm})$ particle size but usually grow during storage time. These nanoparticles are produced by double emulsion: water-oilwater or by single / single oil-water. They can also be prepared by the solvent diffusion method with ethanol and anti-solvent water. These nanoparticles are manufactured from solid or liquid solid and liquid lipids and stabilized by emulsifiers. Lipid nanoparticles can incorporate both hydrophilic and hydrophobic drugs $[53,55]$.
Lipid systems (Figure 2A-D) consist of vesicular structures formed by phospholipids; the most common representatives are liposomes (Figure 2B) and micelles (Figure 2A). Liposomes are small spherical vesicles divided into two major groups: the first based on structural parameters, the second on the method of preparation of the liposome [51]. Both groups are then subdivided in 8 subclasses (Table 1). Several liposomal encapsulated drugs are currently approved by the Food and Drug Administration (FDA) [56-58].

Micelles are generally globular aggregates however these structures may be ellipsoidal, cylindrical, or layered. Micelles may be based on lipids or polymers such as chitosan, chondroitin, or polyethylene glycol (PEG) [51]. Some micellar drug therapy formulations exist and already have FDA approval [58].
A

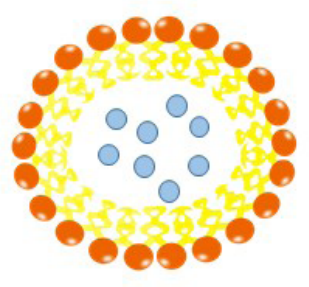

$\mathbf{E}$

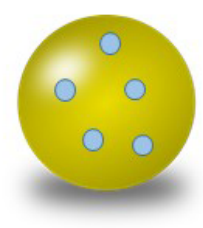

B

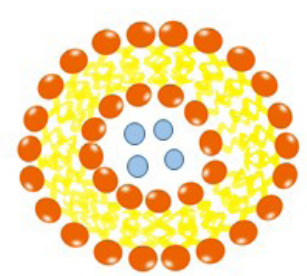

C

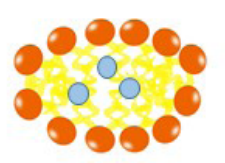

D

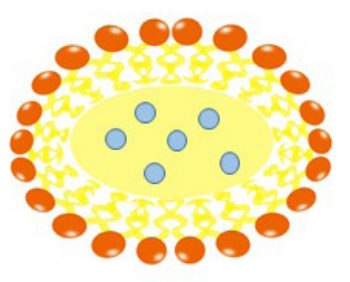

$\mathbf{H}$

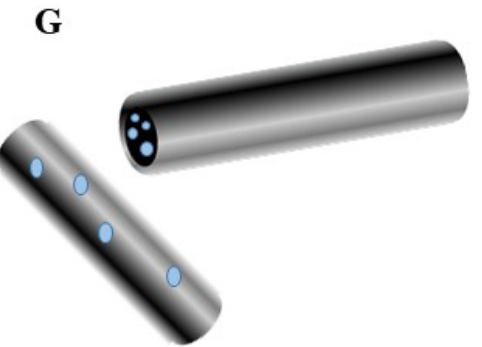

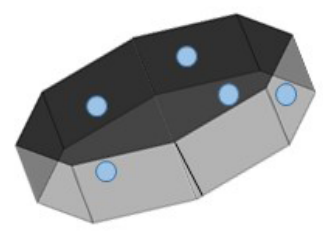

Figure 2 Graphical representations of the structure of various nanoparticulate systems.

(A-D). Lipid Based Systems (A). Micelles (B). Liposomes (C). Lipid Nanodiscs (D). Solid Lipid Nanoparticles (SLN). (E-H). Polymeric and Metallic / Inorganic Systems (E). Nanospheres (F). Nanocapsules / Polymeric Micelles (G). Nanofibers and Nanotubes (H). Nanodiscs.

Table 1 Classification of liposomal delivery systems according to molecule size and mode of preparation.

\begin{tabular}{ll}
\hline Structural Parameters & Method of Preparation \\
\hline Multilamellar large vesicles (MLV) $>0.5 \mu \mathrm{m}$ & OLV made by reverse-phage evaporation (REV) \\
Oligolamellar vesicles (OLV) $0.1-1 \mu \mathrm{m}$ & MLV made by reverse-phage evaporation (MLV-REV) \\
Unilamellar vesicles (all sizes) $(\mathrm{ULV})$ & Stable plurilamellar vesicles (SPLV) \\
Small unilamellar vesicles (SUV) $20-100 \mathrm{~nm}$ & Frozen and thawed MLV (FATMLV) \\
Medium - sized unilamellar vesicles (MUV) & Vesicles prepared by extrusion (VET) \\
Large unilamellar vesicles (LUV) $>100 \mathrm{~nm}$ & Vesicles prepared by French press (FPV) \\
Giant unilamellar vesicles $(\mathrm{GUV})$ with diameters $>1 \mu \mathrm{m}$ & Vesicles prepared by fusion (FUV) \\
Multivesicular vesicles $(\mathrm{MVV})>1 \mu \mathrm{m}$ & Dehydratation-rehydratation vesicles (DRV)
\end{tabular}




\section{Liposomes}

Changing the formulation or delivery system of a drug is referred to as repositioning and it could be useful to increase the efficacy while reducing the toxicity. Using this approach, a recent study showed that miltefosine-encapsulated liposomes are efficient in the treatment of L. major [59]. Another study [60] investigated the action of buparvaquone in vitro and determined the efficacy of liposomes charged with this drug in hamsters infected with L. infantum [60]. Buparvaquone liposomes (BPQ-LP) induce a Th1-type protective immune response over the Th2 response by increasing the levels of cytokines such as tumor necrosis factor and monocyte chemoattractant protein 1 (MCP-1), assisting in the elimination of parasites via production of NO. These results showed that BPQ-LP is a safe and effective treatment for murine leishmaniasis that could potentially also be used against human VL [60]. Liposomes with immunomodulatory properties can present synergistic effect with the drug they encapsulate, have beneficial effects in a variety of different diseases, and seem therefore superior to those that serve merely as delivery systems.

Traditional liposomes (Figure 2B) have been followed by modified vesicles such as transferosomes, also called elastic vesicles. Transferosomes are made of phospholipids and contain an edge activator, which can mediate bilayer deformability. This characteristic allows transferosomes to squeeze in tight places and move through intact skin. Bavarsad, et al. showed that topical treatment with paromycin sulfate transferosomal formulations was more effective than the drug alone and led to smaller lesions and decreased parasitic burden in mice infected with L. major [61].

Another study from Morilla, et al. [62] designed multilamellar liposomes (MLV) composed of hydrogenated soybean phosphatidylcholine, distearoyl-phosphatidylglycerol, and cholesterol, loaded with BZN, a currently approved treatment for Chagas disease. This formulation was more rapidly eliminated from the circulation compared to the free drug. Additionally, due to decreased interactions of this new formulation with plasma proteins and other blood components, the toxic side effects were also reduced. This data shows that MLV BZN is a vehicle potentially capable of improving the treatment with BZN against T. cruzi infection [62]. Another preliminary study [63] showed the superior efficacy of a liposomal preparation of diminazene aceturate, compared to the free compound, in vitro against Trypanosoma evansi, a trypanosome causing equine illness similar to T. brucei in humans. However, in vivo testing was inconclusive, and further studies are required to find a more effective liposomal preparation with greater in vivo efficacy [63]. It has been shown that lipid nanoparticle formulations of diminazine lead to increased trypanocidal activity against T. $b$. brucei as well as an increased stability in vitro, due to protection from oxidation [64].

\section{Micelles}

Micelles (Figure 2A) have been used in a study evaluating the in vitro and in vivo anti-leishmanial activity of 8-hydroxyquinoline in a micelle system against L. infantum. This micelle delivery system led to significant reduction in parasitic burdens and elicited a Th1 immune response, indicated by high levels of IFN- $\gamma$, IL-12, granulocyte-macrophage colony-stimulating factor, nitric oxide and anti-leishmanial IgG1 isotype antibodies [65]. Furthermore, the interaction of 5-nitro-2-furfurilylidene benzhydrazide, a potential anti-trypanosomal compound with micellar solutions, was evaluated by Rangel-Yagui, et al [66]. In this study, the compound was shown to be five times more effective than BZN, the drug of choice for Chagas disease [66]. In a comparative in vivo study of a micellar diminazine formulation against T. evansi, micellar preparations had a higher drug accumulation rate within erythrocytes through greater cell membrane interaction. This resulted not only in greater efficacy, but also allowed for a decreased dose requirement in vivo, indicating great promise for similar preparations made against T. brucei in the human host [67].

\section{Solid lipid nanoparticles (SLN)}

SLN (Figure 2D) were first developed in 1996 and can be classified into three types of structures: SLN, nanostructured lipid carrier (NLC), and lipid-conjugates. These particles are solid at room and body temperature, and compromised of lipids such as glyceryl monostearate and stearic acid [51]. Because SLN contain lipids, they retain a biocompatible and biodegradable profile, but because they are solid and rigid, they allow good protection of the drug incorporated, even in inhospitable environments with great variation of $\mathrm{pH}$, humidity and temperature. SLN have low drug loading efficiency because of the restricted allosteric space. SLN are typically produced using a high pressure homogenization technique. During the storage process, crystallization may occur, which results in drug expulsion from the SLN [68]. Nanostructured lipid carriers (NLCs) are similar to SLN but have a greater ability to incorporate drugs, do not usually crystallize during storage processes and have liquid lipids inside them instead of solid [69]. These particles are ideal for delivering hydrophobic drugs as they are composed entirely of lipids.

A recent study [70] associated SLN with PM, an antileishmanial drug, to improve its effectiveness. PM-SLN were evaluated in vivo against infection of L. major in BALB/c mice. PM-loaded SLN have greater apparent safety compared to the free drug and are more efficient as they increased penetration of the drug into macrophages in addition to enhancing the immune response [70]. In particular, PM-loaded SLN were more efficient than free PM for the treatment of $L$. tropica and the augmentation of a protective immune response in mice [71]. Searching for new therapeutic drugs against T. cruzi, Carneiro, et al.[72] evaluated in vitro and in vivo efficacy of 5-hydroxy-3-methyl-5-phenyl pyrazoline-1 (S-benzyl dithiocarbazate) as a free substance and inside an SLN system. The nanoparticles were effective in reducing the parasitic loads in infected animals and also reduced the inflammatory process in the liver, spleen and heart, and still promoted a survival of $100 \%$ of the infected mice [72]. SLN have 
also shown promising results for the treatment of Trypanosoma spp. infections. In a study comparing in vivo effects of a SLN a-bisabolol preparation using standard diminazine aceturate treatment as well as combination therapy in a T. evansi model, it was found that combination therapy with SLN preparations greatly enhanced curative effects compared with either drug taken alone [73]. Combination therapy such as eflornithinenifurtimox therapy is currently widely used for the treatment of T. brucei infections and so this potential use of SLN to amplify the curative properties of different drugs is of particular interest [74]. Furthermore, nanostructured lipid carrier (NLC) systems can improve efficacy of poorly water-soluble drugs against protozoan diseases. For instance, NLC carrying cedrol have shown improved antiparasitic activity against $L$. donovani in vitro and in vivo compared to treatment with the free drug [75].

\section{Nanodiscs}

Lipid nanodiscs (Figure 2C) are composed of a phospholipid bilayer surrounded by the amphiphilic motifs of apolipoproteins [76]. The efficiency of nanodiscs harboring the toxic and poorly soluble anti-leishmanial agent $\mathrm{AmB}$ was assessed in L. majorinfected BALB/c mice with increased efficacy observed. These results identify nanodiscs as potentially useful delivery systems for the treatment of intra-histiocyte pathogens [76]. Nanodiscs possess similar characteristics to micelles but are smaller and simpler in structure, possibly allowing for easier customization of lipid composition and apolipoproteins as well as more effective cellular internalization.

\section{Polymeric systems}

Polymeric systems (Figure 2E-H) include polymeric nanoparticles such as nanocapsules (Figure $2 \mathrm{~F}$ ) and nanospheres (Figure 2E): which are solid particles in the colloidal state, formed by polymeric materials. The method of preparation may favor the formation of one or the other pharmaceutical forms. Nanospheres are composed of a spherical polymeric matrix, whereas nanocapsules have a polymeric wall and an oleaginous-oily nucleus $[77,78]$. Some polymeric systems have already been approved by the FDA to be used in the treatment of a wide array of diseases $[58,73,74]$. Polymeric particulates are of great interest due to diverse applicability and their ability to act as bio-conductors [79].

\section{Nanocapsules and Polymeric Micelles}

Asthana, et al. show that mannose grafted chitosan nanocapsules (MnosCNc) containing AmB, have high specificity for macrophages, the preferred host cell for Leishmania, and present antiparasitic activity against $L$. donovani in vitro and in vivo [80]. Interestingly, lipid-core nanocapsules have also been used to improve the efficacy of Quercetin against L. amazonensis [81]. In an animal model of HAT, quinapyramine sulfate encapsulated within nanoparticles consisting of chitosan, tripolyphosphate, and mannitol or sodium alginate was shown to have stronger in vivo efficacy against T. evansi than the drug alone, even when lower doses were administered to animals [82-84]. Further, this drug is intended for animal use only, as its side effects are so severe, and this nanocapsule formulation reduced the side effects in animals to a negligible amount. Nevertheless, this reduction in negative side effects in the host demonstrates the need for further study in this area, as there is the possibility that efficient trypanocidal drugs previously overlooked due to severe side effects may be administered in nanocapsule form to mitigate any ill effects. Using a chitosan nanoparticle coated with a nanobody specific for the cell surface of T. brucei, Garcio-Salcedo et al. was able to administer pentamidine in a murine T. brucei model at an effective dose 100-fold lower than the effective dose for the drug alone. Direct targeting allowed for the uptake of the drug through endocytosis, resulting in a drug effective against drug resistant strains [85]. Nanobody formulations such as this may have applications against Leishmania as well, as macrophage specific nanobodies may be utilized to administer anti-leishmanial drugs specifically into the host's macrophages, increasing access to amastigotes. Several studies have characterized various encapsulated formulations of BZN, the current first-line drug for the treatment of Chagas disease. Novel nanostructure BZN carrier efficacy was examined in fibroblasts in vitro as well as in vivo murine models resulting in reduced mammalian cell cytotoxicity, decreased parasite viability and increased survival rates of infected mice [86-89]. Similarly, lychnopholide encapsulated in polymeric nanocapsules was effective in curing chronic phase infection via oral administration and was just as effective as standard BZN treatment during acute phase via intravenous administration in murine models [90, 91].

Nanoencapsulated natural remedies, including tea tree oil, curcumin, and Achyrocline satureioides oil, have all shown greater efficacy against different trypanosome species than non-carrier-based formulations [92-94]. Nanoencapsulated compounds showed greater trypanostatic or trypanocidal effect against T. evansi, with a reduction in side effects and effective dose. Furthermore, nano-encapsulated tea tree oil was shown to improve the in vivo efficacy of diminazine aceturate from just $33 \%$ to $100 \%$, demonstrating the need for further research in drug combination studies involving nano-encapsulated drug formulations.

Polymeric micelles are another type of nanomaterial that has attracted considerable attention as a potential drug carrier. Micelles form spontaneously in aqueous solutions and are composed of amphipathic copolymers. The use of polymeric micelles such as Poloxamer P407 (Pluronic ${ }^{\circledR}$ F127) (Amp/M) and the Ambisome ${ }^{\bowtie}$ formulation (Lip-Amp) have been evaluated as delivery systems for leishmaniasis treatments. It was demonstrated that Amp/M or Lip-Amp treated mice had lower parasitic burden along with a more prominent Th1 immune response compared to the control mice treated with the free drugs; additionally, micelle formulation-treated mice did not develop hepatic or renal damage [95]. 
While polymeric nanocapsules and micelles have similar initial burst drug release kinetics to lipid-based micelles, there is a time delay before drug release as the external polymeric membrane must be degraded. Tuning of polymeric membrane properties such as attached functional groups, molecular weight, and zeta potential allows more customization of drug release than offered by traditional lipid-based micelles [96].

\section{Nanospheres}

Nanospheres constructed using chitosan and chondroitin containing AmB (NQC-AmB) have been studied and tested in animals infected with L. amazonensis, the causative species of CL in the Americas. AmB loaded nanosphere treatment reduced parasitic loads, lesion size, and drug toxicity compared to treatment with free drug alone, indicating that the NQC-AmB system was effective in directed delivery [97]. Interestingly, hemoglobin-guided NQC-AmB has shown reduced LD50 and toxicity in macrophages infected with $L$. donovani compared to those treated with AmB alone [98]. Furthermore, PLGAPEG encapsulated AmB nanospheres have been shown to be more effective and less toxic than free AmB for the treatment of L. donovani infection [99]. Similarly, PLGA-encapsulated desoxycholate AmB was more effective than the free drug for the treatment of mice infected with cutaneous leishmaniasis [100]. Another study showed that artemisin-loaded nanospheres significantly reduced parasitic burdens and hepato-splenomegaly in mice infected with $L$. donovani compared to the group treated with the free drug. These effects were associated with an augmented Th1 response, suggesting that this formulation also possesses immunomodulatory properties [101].

Chitosan nanoparticles (CS NPs) synthesized together with the precursor of nitric oxide in mercaptosuccinic acid (MSA) have been studied in a Chagas disease model. Treatment of peritoneal macrophages with these nanoparticles decreased the number of T. cruzi infected cells and the average number of intracellular replicative amastigotes per infected cell. These results suggest that the S-nitroso-MSA-CS NPs are promising nanocarriers for the treatment of Chagas disease and can deliver nitric oxide intracellularly [102]. Ursolic acid loaded poly-e-caprolactone nanoparticles have also been evaluated in vivo showing similar efficacy to BZN standard formulations [103]. Polymeric antibody delivery systems have also been developed to target T. $b$. gambiense. PEG covalently attached to PLGA and loaded with pentamidine alongside an antibody fragment specifically targeting the $T$. brucei cell wall has shown positive results both in vitro and in vivo with $100 \%$ cure rate of T. b. gambiense infected mice. This outstanding result is even more remarkable as it was obtained using only a tenth of the normal dose of pentamidine. Additionally, a 100-fold decrease in drug concentration still resulted in a $60 \%$ cure rate with this nanosphere delivery system [104]. Polymeric nanospheres contain an even distribution of a given drug throughout the solid polymer matrix and drug release is timed in coordination with matrix degradation and diffusion of the drug. This characteristic makes these particles more suitable for sustained drug release applications, providing a useful application during chronic infection by these parasites or in situations where resurgence of the parasite burden may occur [96].

\section{Nanofibers}

Recent advances in materials science and biochemistry have allowed for the construction of high aspect ratio nanofibers (Figure 2G) using self-assembling peptide amphiphiles. These nanofibers may be incorporated with a targeting motif and have demonstrated ability to adhere to in vivo targets with high specificity. Functionalization of these nanofibers by S-nitrosylation reaction of the cysteine residues of the PAs allowed for targeted and sustained delivery of nitric oxide to a specific site determined by the binding target of the attached targeting-sequence [105].

\section{Metallic / inorganic systems}

Metallic/inorganic systems (Figure 2E-H) have been recently developed and include inorganic nanoparticles, like carbon nanotubes, as well as metallic (metal and metal oxide) nanoparticles composed of different metals such as gold, silver magnesium, titanium, and zinc. Drugs are adsorbed or covalently bound to the surface of these particles which exist as a colloidal suspension in liquid. Drug release from metallic nanoparticles is dictated by the strength of these bonding forces between the desired drug and the surface of the nanoparticle; however, coating of the particle surface with polymers can alter these characteristics. An advantage of metallic systems over other nanoparticle systems is that it is easier to locate cells containing nanoparticles in vivo post-administration using imaging techniques [106, 107].

\section{Nanospheres}

Recent studies have validated the antimicrobial potential of various metals and metal oxides. Jebali, et al. tested different metallic nanoparticles in a CL model caused by L. major, aiming to understand the anti-microbial effects of nanoparticles in the presence or absence of ultra violet (UV)/pIR light utilizing gold (Au NPs), silver (Ag NPs), magnesium (MgO NPs), titanium (TiO2 NPs) and zinc oxide (ZnO NPs) particles. Their findings suggest great potential for these metallic particles in antimicrobial use, which is enhanced by exposure to either UV or IR light [108]. Ag NPs have been identified as a potential therapeutic option as they cause damage to the structural integrity of intracellular L. amazoniensis amastigotes [109]. $\mathrm{ZnO}$ NPs have also showed potential antiparasitic activity against $L$. tropica in vitro, with an $\mathrm{IC}_{50}$ up to 3.76 against promastigotes [110]. A different study [111] investigating the effect of quercetin conjugated AuNP (QAuNP), found that QAuNP efficiently targeted Leishmania amastigotes with a high selectivity index, an indispensable requirement to approve the use of a drug [111]. Potential anti-trypanosomal drugs have also been identified in 
the bioactive pigment molecules prodigiosin and violacein. These two drugs both showed efficacy against T. b. gambiense in vitro and represent a possible new therapeutic against HAT. When these compounds were prepared with metal nanoparticles, IC50 values significantly decreased. In the same study, similar results were seen when this preparation was tested against another pathogenic parasite, Plasmodium falciparum, the causative agent of malaria [112].

Gold and silver nanoparticles have been shown to have high specificity and binding affinity towards arginine kinase of T. brucei [113]. Further, Kato et al. have demonstrated the trypanostatic effect metal nanoparticles have against different species of trypanosome, particularly T. brucei, with high selective activity [114]. Taken together, these observations highlight the potential of metal nanoparticles, particularly gold and silver nanoparticles, against Trypanosoma spp. With high specificity for a kinase present only in Trypanosoma spp., these nanoparticles may be incorporated into other drug formulations, resulting in formulations specifically targeting arginine kinase, and the trypanosomes, allowing for reduced IC50 values and a mitigation of possible side effects for the host.

\section{Nanotubes}

Nanotubes (Figure 2G) are hollow structures which can be formed by inorganic materials such as carbon, titanium, as well as metallic materials like gold and silver. A study examining the anti-leishmanial efficacy of a novel formulation of AmB associated with carbon nanotubes (CNTs), found enhanced targeted killing of Leishmania donovani in vivo and in vitro compared with free AmB [115]. Furthermore, a group from India that has developed a new anti-leishmanial formulation of betulin (BET) associated with CNTs, reported that CNTs with BET showed better cytotoxicity and IC 50\% compared to the control group, further supporting the possibility of nanotubes as an effective drug delivery system [116]. The efficiency of CNTs as a delivery system was also demonstrated for the standard treatment of VL, AmB[117]. Using a hamster VL model, oral AmB administered with nanotubes exhibited 99\% inhibition of parasite growth. CNTs have not been approved for use in humans and testing is at the preclinical stage [117]. Another study tested the potential of polysaccharide (mannose) associated with multi-walled CNTs plus AmB and proved that CNTs can deliver a drug to specific organs where there are elevated numbers of macrophages. These nanotubes provide a more direct and safer way to deliver the drug to the target tissue [118]. CNTs have also been used alongside a protein specific RNA aptamer for use in an aptasensor, which is able to detect proteins at the attomolar $\left(10^{-18} \mathrm{~mol}\right)$ level [119]. This new technology applied to HAT would allow for early detection of the disease, enabling treatment prior to progression to the fatal stage II disease of the central nervous system, and allowing for earlier, more successful treatments of the infection. Once in the central nervous system of the host, treatment becomes far more difficult, as formulations of drugs capable of crossing the blood brain barrier and targeting trypanosomes are extremely limited. However, it has been shown that certain functionalized carbon nanotube formulations are able to increase the ability of a compound to cross the blood brain barrier, which could be used to treat late stage infections of HAT [120].

\section{Conclusion}

Of the 17 official NTDs, this review focuses on the only three protozoan diseases namely, leishmaniasis, Chagas disease and HAT, and these three conditions alone are responsible for the highest death toll amongst all the NTDs [6]. Despite the efforts of the scientific community, there are very few preventive measures to control these diseases and no vaccines against these parasitic infections have been approved for human use [46, 121, 122]. Failure to confer a long-lasting immunity [15, 43, 49], as well as high cost and extended time lines [43] are major challenges against the development of an effective vaccine. Furthermore, the therapeutics available for the treatment of these three NTDs often present toxic side effects [7, 25-27, 45,47] and some of these drugs have been associated with increasing parasitic resistance $[26,28-30]$. Because of the shortcomings of these preventive and therapeutic measures, it is imperative to find new approaches to control these infections.

An efficient approach is to administer an already existing drug using different and novel delivery systems to limit the toxic side effects and enhance the bio-availability and efficacy of the compound. In this review we highlighted different nanoparticulate systems used experimentally for the treatment of the three protozoan NTDs. Nanoparticulate drug delivery systems of lipid, polymeric or metallic composition have emerged as a promising area of research, as scientific evidence shows that they can improve the ability to specifically target pathogens, penetrate barriers within the host allowing a drug to access areas of pathogen residence, and reduce toxicity by lowering dose amount and frequency of administration [120, 123, 124]. In general, nanoparticulate systems can possess multiple synergistic functions while maintaining high specificity and selectivity. To improve bio-availability and efficacy, as well as to treat multiple diseases with the same formulations, scientists have been testing co-delivery systems, using the same delivery system to encapsulate multiple drugs with synergistic properties [125-127]. Synergy is already exploited in the treatment of HAT through the combined use of nifurtimox and eflornithine, and as such these multi-drug encapsulations may be particularly effective against this parasite, though further studies are required. These delivery systems also have the potential to directly target the immune system, as well as the parasites themselves. For example, nitric oxide acts as an endogenous signaling molecule influencing host immune responses to protozoan parasites in a positive manner and promoting subsequent reduction of parasitic burden. It has been shown that systemically administered nanoparticles possess the capability to release nitric oxide at targeted sites within the body or intracellularly within macrophages [102, 105]. 
Given the beneficial effect of nitric oxide on protozoan disease progression, nitric oxide releasing functionalized nanoparticles present possible alternatives to traditional toxic front-line chemotherapeutic options. Furthermore, this review focused mainly on treatment strategies, but several studies suggest that lipid, polymeric and metallic nanoparticulate systems could also be used for the delivery of vaccines against the three protozoan NTDs $[128,129]$. Interestingly, lipid systems have also shown promise as vaccine adjuvants, by enhancing the immune response to vaccines [130].

Despite having many positive qualities for parasite treatment, nanoparticles must overcome some challenges to be effectively and widely employed in clinical medicine. Limitations are associated with preparation methods, elimination pathways as well as the lack of knowledge on mechanisms of action [131, 132], each of which poses as an area of interest, requiring further study by the scientific community. Nevertheless, repositioning via nanoparticulate systems appears to be a promising approach to reduce the risks and downfalls associated with the currently available therapeutic compounds.

\section{Abbreviations}

AmB: Amphotericin B; BZN: Benznidazole; BET: Betulin; BPQLP: Buparvaquone liposome; CNTs: Carbon nanotubes; CS NPs: Chitosan Nanoparticles; CL: Cutaneous Leishmaniasis; FDA: Food and Drug Administration; AuNP: Gold nanoparticle; HAT: Human African Trypanosomiasis; IFN- $\gamma$ : Interferon gamma; Interleukin: IL; L.: Leishmania; MgO NPs: Magnesium Nanoparticles; MCP-1: monocyte chemoattractant protein; MLV: Multilamellar vacuoles; NQC-AmB: Nanoparticle Chitosan, Chondroitin, Amphotericin; NTD: Neglected Tropical Disease; NO: Nitric Oxide; PEG: Polyethylene glycol; QAuNP: Quercetin-gold nanoparticle; Ag NPs: Silver Nanoparticles; SLN: Solid lipid nanoparticles; TiO2 NPs: Titanium Nanoparticles; T.: Trypanosoma; UV: Ultra violet; VSG: Variable surface glycoprotein; VL: Visceral leishmaniasis; ZnO NPs: Zinc oxide Nanoparticles.

\section{Availability of data and material}

Not applicable.

\section{Funding}

This work was partly supported by National Institute of Health, National Cancer Institute (NIH/NCI) Career Development Grant K01CA207599 awarded to SO. Moreover, this publication was supported by the Coordination for the Improvement of Higher Education Personnel (CAPES) through "Programa Editoração CAPES” - call No. 3/2016, grant No. 0722/2017, record No. $88881.142062 / 2017-01$ and by the National Council for Scientific and Technological Development (CNPq) and Coordination for the Improvement of Higher Education Personnel (CAPES) through “Programa Editorial CNPq/CAPES" call No. 18/2018, grant No. 404770/2018-5.

\section{Competing interests}

The authors declare they have no competing interests.

\section{Authors' contributions}

GV and LC contributed equally to the writing of the manuscript. NR wrote and organized the manuscript. GH generated the figures and organized the manuscript. AS and SO wrote, organized and reviewed the manuscript. All authors have approved the final manuscript before submission.

\section{Ethics approval and consent to participate}

Not applicable.

\section{Consent for publication}

Not applicable.

\section{References}

1. Buscaglia CA, Kissinger JC, Aguero F. Neglected tropical diseases in the post-genomic era. Trends Genet. 2015;31(10):539-555. Available from: https://doi.org/10.1016/j.tig.2015.06.002

2. Okwor I, Uzonna J. Social and economic burden of human leishmaniasis. Am J Trop Med Hyg. 2016;94(3):489-493. Available from:https://doi. org/10.4269/ajtmh.15-0408

3. Franco JR, Simarro PP, Diarra A, Jannin JG. Epidemiology of human African trypanosomiasis. Clin Epidemiol. 2014;6:257-275.

4. Utzinger J, Becker SL, Knopp S, et al. Neglected tropical diseases: diagnosis, clinical management, treatment and control. Swiss Med Wkly. 2012;142:w13727. Available from: https://doi.org/10.4414/ smw.2012.13727

5. Hotez PJ. Ten failings in global neglected tropical diseases control PLoS Negl Trop Dis. 2017;11(12):e0005896. Available from: https:// doi.org/10.1371/journal.pntd.0005896

6. Hotez PJ, Molyneux DH, Fenwick A, et al. Control of neglected tropical diseases. N Engl J Med. 2007;357(10):1018-1027. Available from: https:// doi.org/10.1056/NEJMra064142

7. McGwire BS, Satoskar AR. Leishmaniasis: clinical syndromes and treatment. QJM. 2014;107(1):7-14. Available from: https://doi.org/10.1093/ qjmed/hct116

8. Pace D. Leishmaniasis. J Infect. 2014;69(suppl 1):S10-S18. Available from: https://doi.org/10.1016/j.jinf.2014.07.016

9. Chappuis F, Sundar S, Hailu A, et al. Visceral leishmaniasis: what are the needs for diagnosis, treatment and control? Nat Rev Microbiol. 2007;5(11):873-882. Available from: https://doi.org/10.1038/nrmicro1748

10. Desjeux P. Leishmaniasis: Public health aspects and control. Clin Dermatol. 1996;14(5):417-423. Available from: https://doi.org/10.1016/0738081X(96)00057-0

11. Lafuse WP, Story R, Mahylis J, et al. Leishmania donovani infection induces anemia in hamsters by differentially altering erythropoiesis in bone marrow and spleen. PLoS One. 2013;8(3):e59509. Available from: https://doi.org/10.1371/journal.pone.0059509

12. Lezama-Dávila CM, Pan L, Isaac-Márquez AP, et al. Pentalinon andrieuxii root extract is effective in the topical treatment of cutaneous leishmaniasis caused by Leishmania mexicana. Phytother Res. 2014;28(6):909-916. Available from: https://doi.org/10.1002/ptr.5079 
13. Naman CB, Gomes CM, Gupta G. Phytodrugs and Immunomodulators for the Therapy of Leishmaniasis A2. In: Mandal V, Konishi T, eds. Natural Products and Drug Discovery. Elsevier; 2018:213-275:chap 9. Available from: https://doi.org/10.1016/B978-0-08-102081-4.00009-5

14. Smelt SC, Cotterell SE, Engwerda CR, Kaye PM. B cell-deficient mice are highly resistant to Leishmania donovani infection, but develop neutrophil-mediated tissue pathology. J Immunol. 2000;164(7):36813688. Available from: https://doi.org/10.4049/jimmunol.164.7.3681

15. Srivastava S, Shankar P, Mishra J, Singh S. Possibilities and challenges for developing a successful vaccine for leishmaniasis. Parasit Vectors. 2016;9(1):277. Available from: https://doi.org/10.1186/s13071-016-1553-y

16. Dey R, Natarajan G, Bhattacharya P, et al. Characterization of crossprotection by genetically modified live-attenuated Leishmania donovani parasites against Leishmania mexicana. J Immunol. 2014;193(7):35133527. Available from: https://doi.org/10.4049/jimmunol.1303145

17. Fiuza JA, Santiago HC, Selvapandiyan A, et al. Induction of immunogenicity by live attenuated Leishmania donovani centrin deleted parasites in dogs. Vaccine. 2013;31(14):1785-1792. Available from: https://doi.org/10.1016/j. vaccine.2013.01.048

18. Selvapandiyan A, Dey R, Nylen S, Duncan R, et al. Intracellular replication-deficient Leishmania donovani induces long lasting protective immunity against visceral leishmaniasis. J Immunol. 2009;183(3):18131820. Available from: https://doi.org/10.4049/jimmunol.0900276

19. Das A, Ali N. Vaccine development against Leishmania donovani. Front Immunol. 2012;3:99. Available from: https://doi.org/10.3389/ fimmu.2012.00099

20. Costa LE, Chávez-Fumagalli MA, Martins VT, et al. Phage-fused epitopes from Leishmania infantum used as immunogenic vaccines confer partial protection against Leishmania amazonensis infection. Parasitology. 2015;142(10):1335-1347. Available from: https://doi.org/10.1017/ S0031182015000724

21. Costa LE, Salles BCS, Santos TTO, et al. Antigenicity of phage clones and their synthetic peptides for the serodiagnosis of canine and human visceral leishmaniasis. Microb Pathog. 2017;110:14-22. Available from: https://doi.org/10.1016/j.micpath.2017.06.020

22. Zanin FHC, Coelho EAF, Tavares CAP, et al. Evaluation of immune responses and protection induced by $\mathrm{A} 2$ and nucleoside hydrolase $(\mathrm{NH})$ DNA vaccines against Leishmania chagasi and Leishmania amazonensis experimental infections. Microbes Infect. 2007;9(9):1070-1077. Available from: https://doi.org/10.1016/j.micinf.2007.05.012

23. Samant M, Gupta R, Kumari S, et al. Immunization with the DNAencoding $\mathrm{N}$-terminal domain of proteophosphoglycan of Leishmania donovani generates Th1-type immunoprotective response against experimental visceral leishmaniasis. J Immunol. 2009;183(1):470-479. Available from: https://doi.org/10.4049/jimmunol.0900265

24. Guha R, Das S, Ghosh J, et al. Heterologous priming-boosting with DNA and vaccinia virus expressing kinetoplastid membrane protein-11 induces potent cellular immune response and confers protection against infection with antimony resistant and sensitive strains of Leishmania (Leishmania) donovani. Vaccine. 2013;31(15):1905-1915. Available from: https://doi.org/10.1016/j.vaccine.2013.02.025

25. Wolf Nassif P, De Mello TFP, Navasconi TR, et al. Safety and efficacy of current alternatives in the topical treatment of cutaneous leishmaniasis: a systematic review. Parasitology. 2017;144(8):995-1004. Available from: https://doi.org/10.1017/S0031182017000385

26. Singh N, Kumar M, Singh RK. Leishmaniasis: current status of available drugs and new potential drug targets. Asian Pac J Trop Med. 2012;5(6):485-497. Available from: https://doi.org/10.1016/S19957645(12)60084-4

27. de Menezes JPB, Guedes CES, Petersen ALOA, Fraga DBM, Veras PST. Advances in development of new treatment for Leishmaniasis. BioMed Res Int. 2015;2015(815023):1-11. Available from: https://doi. org/10.1155/2015/815023

28. Sundar S, More DK, Singh MK, et al. Failure of pentavalent antimony in visceral leishmaniasis in India: report from the center of the Indian epidemic. Clin Infect Dis. 2000;31(4):1104-1107. Available from: https:// doi.org/10.1086/318121
29. Polonio T, Efferth T. Leishmaniasis: drug resistance and natural products [review]. Int J Mol Med. 2008;22(3):277-286.

30. Lira R, Sundar S, Makharia A, et al. Evidence that the high incidence of treatment failures in Indian kala-azar is due to the emergence of antimony-resistant strains of Leishmania donovani. J Infect Dis. 1999;180(2):564-567. Available from: https://doi.org/10.1086/314896

31. Andrade DV, Gollob KJ, Dutra WO. Acute chagas disease: new global challenges for an old neglected disease. PLoS Negl Trop Dis. 2014;8(7):e3010. Available from: https://doi.org/10.1371/journal. pntd.0003010

32. Conners EE, Vinetz JM, Weeks JR, Brouwer KC. A global systematic review of Chagas disease prevalence among migrants. Acta Trop. 2016;156:6878. Available from: https://doi.org/10.1016/j.actatropica.2016.01.002

33. Pereira PC, Navarro EC. Challenges and perspectives of Chagas disease: a review. J Venom Anim Toxins Incl Trop Dis. 2013;19(1):34. Available from: https://doi.org/10.1186/1678-9199-19-34

34. Sales Junior PA, Molina I, Fonseca Murta SM, et al. Experimental and clinical treatment of Chagas Disease: A review. Am J Trop Med Hyg. 2017;97(5):1289-1303. Available from: https://doi.org/10.4269/ ajtmh.16-0761

35. Reisenman CE, Lawrence G, Guerenstein PG, Gregory T, Dotson E, Hildebrand JG. Infection of kissing bugs with Trypanosoma cruzi, Tucson, Arizona, USA. Emerg Infect Dis. 2010;16(3):400-405. Available from: https://doi.org/10.3201/eid1603.090648

36. Gascon J, Bern C, Pinazo MJ. Chagas disease in Spain, the United States and other non-endemic countries. Acta Trop. 2010;115(1-2):22-27. Available from: https://doi.org/10.1016/j.actatropica.2009.07.019

37. Bern C. Chagas' Disease. N Engl J Med. 2015;373(5):456-466. Available from: https://doi.org/10.1056/NEJMra1410150

38. Stanaway JD, Roth G. The burden of Chagas disease: estimates and challenges. Glob Heart. 2015;10(3):139-144. Available from: https://doi. org/10.1016/j.gheart.2015.06.001

39. Rassi AJr. Rassi A, Marin-Neto JA. Chagas disease. Lancet. 2010;375(9723):1388-1402.

40. Tarleton RL. CD8+ T cells in Trypanosoma cruzi infection. Semin Immunopathol. 2015;37(3):233-238. Available from: https://doi. org/10.1007/s00281-015-0481-9

41. Cai CW, Blasé JR, Zhang X, Eickhoff CS, Hoft DF. Th17 cells are more protective than Th1 cells against the intracellular parasite Trypanosoma cruzi. PLoS Pathog. 2016;12(10):e1005902. Available from: https://doi. org/10.1371/journal.ppat.1005902

42. Bucheton B, MacLeod A, Jamonneau V. Human host determinants influencing the outcome of Trypanosoma brucei gambiense infections. Parasite Immunol. 2011;33(8):438-447. Available from: https://doi. org/10.1111/j.1365-3024.2011.01287.x

43. Rodríguez-Morales $\mathrm{O}$, Monteón-Padilla $\mathrm{V}$, Carrillo-Sánchez SC, et al. Experimental vaccines against Chagas Disease: A Journey through History. J Immunol Res. 2015;2015:489758. Available from: https://doi. org/10.1155/2015/489758

44. Miyahira Y. Trypanosoma cruzi infection from the view of CD8+ $T$ cell immunity - an infection model for developing $T$ cell vaccine. Parasitol Int. 2008;57(1):38-48. Available from: https://doi.org/10.1016/j. parint.2007.07.005

45. Bern C, Montgomery SP, Herwaldt BL, et al. Evaluation and treatment of chagas disease in the United States: a systematic review. JAMA. 2007;298(18):2171-2181. Available from: https://doi.org/10.1001/ jama.298.18.2171

46. Lejon V, Bentivoglio M, Franco JR. Human African trypanosomiasis. Handb Clin Neurol. 2013;114:169-181. Available from: https://doi. org/10.1016/B978-0-444-53490-3.00011-X

47. Kennedy PG. Clinical features, diagnosis, and treatment of human African trypanosomiasis (sleeping sickness). Lancet Neurol. 2013;12(2):186-194. Available from: https://doi.org/10.1016/S1474-4422(12)70296-X

48. Leppert BJ, Mansfield JM, Paulnock DM. The soluble variant surface glycoprotein of African trypanosomes is recognized by a macrophage scavenger receptor and induces I kappa B alpha degradation independently 
of TRAF6-mediated TLR signaling. J Immunol. 2007;179(1):548-556. Available from: https://doi.org/10.4049/jimmunol.179.1.548

49. Black SJ, Mansfield JM. Prospects for vaccination against pathogenic African trypanosomes. Parasite Immunol. 2016;38(12):735-743. Available from: https://doi.org/10.1111/pim.12387

50. Büscher P, Cecchi G, Jamonneau V, Priotto G. Human African trypanosomiasis. Lancet. 2017;390(10110):2397-2409. Available from: https://doi.org/10.1016/S0140-6736(17)31510-6

51. Wissing SA, Kayser O, Müller RH. Solid lipid nanoparticles for parenteral drug delivery. Adv Drug Deliv Rev. 2004;56(9):1257-1272. Available from: https://doi.org/10.1016/j.addr.2003.12.002

52. Petros RA, DeSimone JM. Strategies in the design of nanoparticles for therapeutic applications. Nat Rev Drug Discov. 2010;9(8):615-627. Available from: https://doi.org/10.1038/nrd2591

53. Luo Y, Chen D, Ren L, Zhao X, Qin J. Solid lipid nanoparticles for enhancing vinpocetine's oral bioavailability. J Control Release. 2006;114(1):53-59. Available from: https://doi.org/10.1016/j.jconrel.2006.05.010

54. Müller RH, Mader K, Gohla S. Solid lipid nanoparticles (SLN) for controlled drug delivery - a review of the state of the art. Eur J Pharm Biopharm. 2000;50(1):161-177. Available from: https://doi.org/10.1016/ S0939-6411(00)00087-4

55. zur Mühlen A, Schwarz C, Mehnert W. Solid lipid nanoparticles (SLN) for controlled drug delivery-drug release and release mechanism. Eur J Pharm Biopharm. 1998;45(2):149-155. Available from: https://doi. org/10.1016/S0939-6411(97)00150-1

56. Davis ME, Chen ZG, Shin DM. Nanoparticle therapeutics: an emerging treatment modality for cancer. Nat Rev Drug Discov. 2008;7(9):771-782. Available from: https://doi.org/10.1038/nrd2614

57. Park J, Fong PM, Lu J, et al. PEGylated PLGA nanoparticles for the improved delivery of doxorubicin. Nanomedicine (Lond). 2009;5(4):410418. Available from: https://doi.org/10.1016/j.nano.2009.02.002

58. Berry G, Billingham M, Alderman E, et al. The use of cardiac biopsy to demonstrate reduced cardiotoxicity in AIDS Kaposi's sarcoma patients treated with pegylated liposomal doxorubicin. Ann Oncol. 1998;9(7):711716. Available from: https://doi.org/10.1023/A:1008216430806

59. Momeni A, Rasoolian M, Momeni A, et al. Development of liposomes loaded with anti-leishmanial drugs for the treatment of cutaneous leishmaniasis. J Liposome Res. 2013;23(2):134-144. Available from: https://doi.org/10.3109/08982104.2012.762519

60. da Costa-Silva TA, Galisteo AJ Jr, Lindoso JA, Barbosa LR, Tempone AG. Nanoliposomal buparvaquone immunomodulates Leishmania infantum-infected macrophages and is highly effective in a murine model. Antimicrob Agents Chemother. 2017;61(4):e02297-e16. Available from: https://doi.org/10.1128/AAC.02297-16

61. Bavarsad N, Fazly Bazzaz BS, Khamesipour A, Jaafari MR. Colloidal, in vitro and in vivo anti-leishmanial properties of transfersomes containing paromomycin sulfate in susceptible BALB/c mice. Acta Trop. 2012;124(1):33-41. Available from; https://doi.org/10.1016/j. actatropica.2012.06.004

62. Morilla MJ, Prieto MJ, Romero EL. Benznidazole vs benznidazole in multilamellar liposomes: how different they interact with blood components? Mem Inst Oswaldo Cruz. 2005;100(2):213-219. Available from: https://doi.org/10.1590/S0074-02762005000200017

63. Oliveira CB, Rigo LA, Rosa LD, et al. Liposomes produced by reverse phase evaporation: in vitro and in vivo efficacy of diminazene aceturate against Trypanosoma evansi. Parasitology. 2014;141(6):761-769. Available from: https://doi.org/10.1017/S0031182013002114

64. Kroubi M, Daulouede S, Karembe $\mathrm{H}$, et al. Development of a nanoparticulate formulation of diminazene to treat African trypanosomiasis. Nanotechnology. 2010;21(50):505102. Available from: https://doi.org/10.1088/0957-4484/21/50/505102

65. Duarte MC, Lage LM, Lage DP, et al. Treatment of murine visceral leishmaniasis using an 8-hydroxyquinoline-containing polymeric micelle system. Parasitol Int. 2016;65(6)(6 Pt A):728-736. https://doi. org/10.1016/j.parint.2016.07.005

66. Rangel-Yagui CO, Hsu HW, Barbosa LR, et al. Novel potential drug against T. cruzi and its interaction with surfactant micelles. Pharm
Dev Technol. 2007;12(2):183-192. Available from: https://doi. org/10.1080/10837450701212727

67. Staroverov SA, Sidorkin VA, Fomin AS, Shchyogolev SY, Dykman LA. Biodynamic parameters of micellar diminazene in sheep erythrocytes and blood plasma. J Vet Sci. 2011;12(4):303-307. Available from: https:// doi.org/10.4142/jvs.2011.12.4.303

68. Silva AC, González-Mira E, García ML, et al. Preparation, characterization and biocompatibility studies on risperidone-loaded solid lipid nanoparticles (SLN): high pressure homogenization versus ultrasound. Colloids Surf B Biointerfaces. 2011;86(1):158-165. Available from: https:// doi.org/10.1016/j.colsurfb.2011.03.035

69. Beloqui A, Solinís MÁ, Rodríguez-Gascón A, Almeida AJ, Préat V. Nanostructured lipid carriers: promising drug delivery systems for future clinics. Nanomedicine (Lond). 2016;12(1):143-161. Available from: https://doi.org/10.1016/j.nano.2015.09.004

70. Heidari-Kharaji M, Taheri T, Doroud D, Habibzadeh S, Badirzadeh A, Rafati S. Enhanced paromomycin efficacy by solid lipid nanoparticle formulation against Leishmania in mice model. Parasite Immunol. 2016;38(10):599-608. Available from: https://doi.org/10.1111/pim.12340

71. Heidari-Kharaji M, Taheri T, Doroud D, Habibzadeh S, Rafati S. Solid lipid nanoparticle loaded with paromomycin: in vivo efficacy against Leishmania tropica infection in BALB/c mice model. Appl Microbiol Biotechnol. 2016;100(16):7051-7060. Available from: https://doi. org/10.1007/s00253-016-7422-y

72. Carneiro ZA, da S Maia PI, Sesti-Costa R, et al. In vitro and in vivo trypanocidal activity of H2bdtc-loaded solid lipid nanoparticles. PLoS Negl Trop Dis. 2014;8(5):e2847. Available from: https://doi.org/10.1371/ journal.pntd.0002847

73. Baldissera MD, Grando TH, de Souza CF, et al. A nanotechnology based new approach for Trypanosoma evansi chemotherapy: in vitro and vivo trypanocidal effect of (-)-alpha-bisabolol. Exp Parasitol. 2016;170:156160. Available from: Available from: https://doi.org/10.1016/j. exppara.2016.09.018

74. Priotto G, Kasparian S, Mutombo W, et al. Nifurtimox-eflornithine combination therapy for second-stage African Trypanosoma brucei gambiense trypanosomiasis: a multicentre, randomised, phase III, noninferiority trial. Lancet. 2009;374(9683):56-64. Available from: https:// doi.org/10.1016/S0140-6736(09)61117-X

75. Kar N, Chakraborty S, De AK, Ghosh S, Bera T. Development and evaluation of a cedrol-loaded nanostructured lipid carrier system for in vitro and in vivo susceptibilities of wild and drug resistant Leishmania donovani amastigotes. Eur J Pharm Sci. 2017;104:196-211. Available from: https://doi.org/10.1016/j.ejps.2017.03.046

76. Nelson KG, Bishop JV, Ryan RO, Titus R. Nanodisk-associated amphotericin $B$ clears Leishmania major cutaneous infection in susceptible BALB/c mice. Antimicrob Agents Chemother. 2006;50(4):1238-1244. Available from: https://doi.org/10.1128/AAC.50.4.1238-1244.2006

77. Verrecchia T, Huve P, Bazile D, Veillard M, Spenlehauer G, Couvreur $P$. Adsorption/desorption of human serum albumin at the surface of poly(lactic acid) nanoparticles prepared by a solvent evaporation process. J Biomed Mater Res. 1993;27(8):1019-1028. Available from: https://doi. org/10.1002/jbm.820270807

78. Sánchez A, Vila-Jato JL, Alonso MJ. Development of biodegradable microspheres and nanospheres for the controlled release of cyclosporin A. Int J Pharm. 1993;99(2-3):263-273. Available from: https://doi. org/10.1016/0378-5173(93)90369-Q

79. Greiner A, Wendorff JH, Yarin AL, Zussman E. Biohybrid nanosystems with polymer nanofibers and nanotubes. Appl Microbiol Biotechnol. 2006;71(4):387-393. Available from: https://doi.org/10.1007/s00253006-0356-z

80. Asthana S, Gupta PK, Jaiswal AK, Dube A, Chourasia MK. Overexpressed macrophage mannose receptor targeted nanocapsules- mediated cargo delivery approach for eradication of resident parasite: in vitro and in vivo studies. Pharm Res. 2015;32(8):2663-2677. Available from: https:// doi.org/10.1007/s11095-015-1651-0

81. Sousa-Batista AJ, Poletto FS, Philipon CIMS, Guterres SS, Pohlmann AR, Rossi-Bergmann B. Lipid-core nanocapsules increase the oral efficacy of 
quercetin in cutaneous leishmaniasis. Parasitology. 2017;144(13):17691774. Available from: https://doi.org/10.1017/S003118201700097X

82. Manuja A, Kumar B, Kumar R, Chopra M, Dilbaghi N, Kumar $\mathrm{S}$, et al. Encapsulated quinapyramine sulfate-loaded chitosan/ mannitol nanoparticles: biocompatibility and targeting efficiency in rabbit model of trypanosomosis. Antimicrob Agents Chemother. 2018;62(11):AAC.00466.

83. Manuja A, Kumar S, Dilbaghi N, et al. Quinapyramine sulfate-loaded sodium alginate nanoparticles show enhanced trypanocidal activity. Nanomedicine (Lond). 2014;9(11):1625-1634. Available from: https:/l doi.org/10.2217/nnm.13.148

84. Manuja A, Kumar B, Chopra M, et al. Cytotoxicity and genotoxicity of a trypanocidal drug quinapyramine sulfate loaded-sodium alginate nanoparticles in mammalian cells. Int J Biol Macromol. 2016;88:146-155. Available from: https://doi.org/10.1016/j.ijbiomac.2016.03.034

85. Unciti-Broceta JD, Arias JL, Maceira J, et al. Specific cell targeting therapy bypasses drug resistance mechanisms in African trypanosomiasis. PLoS Pathog. 2015;11(6):e1004942. Available from: https://doi.org/10.1371/ journal.ppat.1004942

86. Vinuesa T, Herráez R, Oliver L, et al. Benznidazole Nanoformulates: A chance to improve therapeutics for chagas disease. Am J Trop Med Hyg. 2017;97(5):1469-1476. Available from: https://doi.org/10.4269/ ajtmh.17-0044

87. Tessarolo LD, de Menezes RRPPB, Mello CP, et al. Nanoencapsulation of benznidazole in calcium carbonate increases its selectivity to Trypanosoma cruzi. Parasitology. 2018;145(9):1191-1198. Available from: https://doi.org/10.1017/S0031182018000197

88. Scalise ML, Arrúa EC, Rial MS, Esteva MI, Salomon CJ, Fichera LE. Promising efficacy of benznidazole nanoparticles in acute Trypanosoma cruzi murine model: in-vitro and in-vivo studies. Am J Trop Med Hyg. 2016;95(2):388-393. Available from: https://doi.org/10.4269/ ajtmh.15-0889

89. Rial MS, Scalise ML, Arrúa EC, Esteva MI, Salomon CJ, Fichera LE. Elucidating the impact of low doses of nano-formulated benznidazole in acute experimental Chagas disease. PLoS Negl Trop Dis. 2017;11(12):e0006119. Available from: https://doi.org/10.1371/journal. pntd.0006119

90. Branquinho RT, Mosqueira VC, Oliveira-Silva JC de, Simões-Silva MR, Saúde-Guimarães DA, Lana M de. Sesquiterpene lactone in nanostructured parenteral dosage form is efficacious in experimental Chagas disease. Antimicrob Agents Chemother. 2014;58(4):2067-2075. Available from: https://doi.org/10.1128/AAC.00617-13

91. de Mello CG, Branquinho RT, Oliveira MT, et al. Efficacy of Lychnopholide polymeric nanocapsules after oral and intravenous administration in murine experimental Chagas disease. Antimicrob Agents Chemother. 2016;60(9):5215-5222. https://doi.org/10.1128/AAC.00178-16

92. Do Carmo GM, Baldissera MD, Vaucher RA, et al. Effect of the treatment with Achyrocline satureioides (free and nanocapsules essential oil) and diminazene aceturate on hematological and biochemical parameters in rats infected by Trypanosoma evansi. Exp Parasitol. 2015;149:39-46. Available from: https://doi.org/10.1016/j.exppara.2014.12.005

93. Gressler LT, Oliveira CB, Coradini K, et al. Trypanocidal activity of free and nanoencapsulated curcumin on Trypanosoma evansi. Parasitology. 2015;142(3):439-448. https://doi.org/10.1017/S0031182014001292

94. Baldissera MD, da Silva AS, Oliveira CB, et al. Trypanocidal action of tea tree oil (Melaleuca alternifolia) against Trypanosoma evansi in vitro and in vivo used mice as experimental model. Exp Parasitol. 2014;141:21-27. Available from: https://doi.org/10.1016/j.exppara.2014.03.007

95. Mendonça DVC, Martins VT, Lage DP, et al. Comparing the therapeutic efficacy of different amphotericin B-carrying delivery systems against visceral leishmaniasis. Exp Parasitol. 2018;186:24-35. Available from: https://doi.org/10.1016/j.exppara.2018.02.003

96. Singh R, Lillard JW Jr. Nanoparticle-based targeted drug delivery. Exp Mol Pathol. 2009;86(3):215-223. Available from: https://doi.org/10.1016/j. yexmp.2008.12.004

97. Ribeiro TG, Franca JR, Fuscaldi LL, et al. An optimized nanoparticle delivery system based on chitosan and chondroitin sulfate molecules reduces the toxicity of amphotericin $B$ and is effective in treating tegumentary leishmaniasis. Int J Nanomedicine. 2014;9:5341-5353.

98. Bose PP, Kumar P, Dwivedi MK. Hemoglobin guided nanocarrier for specific delivery of amphotericin B to Leishmania infected macrophage. Acta Trop. 2016;158:148-159. Available from: https://doi.org/10.1016/j. actatropica.2016.02.026

99. Kumar R, Sahoo GC, Pandey K, Das V, Das P. Study the effects of PLGA-PEG encapsulated amphotericin $B$ nanoparticle drug delivery system against Leishmania donovani. Drug Deliv. 2015;22(3):383-388. Available from: https://doi.org/10.3109/10717544.2014.891271

100. de Carvalho RF, Ribeiro IF, Miranda-Vilela AL, et al. Leishmanicidal activity of amphotericin B encapsulated in PLGA-DMSA nanoparticles to treat cutaneous leishmaniasis in C57BL/6 mice. Exp Parasitol. 2013;135(2):217222. Available from: https://doi.org/10.1016/j.exppara.2013.07.008

101. Want MY, Islamuddin M, Chouhan G, et al. Therapeutic efficacy of artemisinin-loaded nanoparticles in experimental visceral leishmaniasis. Colloids Surf B Biointerfaces. 2015;130:215-221. Available from: https:// doi.org/10.1016/j.colsurfb.2015.04.013

102. Contreras Lancheros CA, Pelegrino MT, Kian D, et al. Selective antiprotozoal activity of nitric oxide-releasing chitosan nanoparticles against Trypanosoma cruzi: toxicity and mechanisms of action. Curr Pharm Des. 2018;24(7):830-839. Available from: https://doi.org/10.21 74/1381612824666180209105625

103. Abriata JP, Eloy JO, Riul TB, Campos PM, Baruffi MD, Marchetti JM. Polyepsilon-caprolactone nanoparticles enhance ursolic acid in vivo efficacy against Trypanosoma cruzi infection. Mater Sci Eng C. 2017;77:1196-1203. Available from: https://doi.org/10.1016/j.msec.2017.03.266

104. Arias JL, Unciti-Broceta JD, Maceira J, et al. Nanobody conjugated PLGA nanoparticles for active targeting of African Trypanosomiasis. J Control Release. 2015;197:190-198. Available from: https://doi.org/10.1016/j. jconrel.2014.11.002

105. Bahnson ES, Kassam HA, Moyer TJ, et al. Targeted nitric oxide delivery by supramolecular nanofibers for the prevention of restenosis after arterial injury. Antioxid Redox Signal. 2016;24(8):401-418. Available from:https://doi.org/10.1089/ars.2015.6363

106. Meir R, Motiei M, Popovtzer R. Gold nanoparticles for in vivo cell tracking. Nanomedicine (Lond). 2014;9(13):2059-2069. Available from: https://doi.org/10.2217/nnm.14.129

107. Kong FY, Zhang JW, Li RF, et al. Unique roles of gold nanoparticles in drug delivery, targeting and imaging applications. Molecules. 2017;22(9):1445. Available from: https://doi.org/10.3390/molecules22091445

108. Jebali A, Kazemi B. Nano-based antileishmanial agents: a toxicological study on nanoparticles for future treatment of cutaneous leishmaniasis. Toxicol In Vitro. 2013;27(6):1896-1904. Available from: https://doi. org/10.1016/j.tiv.2013.06.002

109. Fanti JR, Tomiotto-Pellissier F, Miranda-Sapla MM, et al. Biogenic silver nanoparticles inducing Leishmania amazonensis promastigote and amastigote death in vitro. Acta Trop. 2018;178:46-54. Available from: https://doi.org/10.1016/j.actatropica.2017.10.027

110. Ali A, Ambreen S, Javed R, Tabassum S, UI Haq I, Zia M. ZnO nanostructure fabrication in different solvents transforms physio-chemical, biological and photodegradable properties. Mater Sci Eng C. 2017;74:137-145. Available from: https://doi.org/10.1016/j.msec.2017.01.004

111. Das S, Roy P, Mondal S, Bera T, Mukherjee A. One pot synthesis of gold nanoparticles and application in chemotherapy of wild and resistant type visceral leishmaniasis. Colloids Surf B Biointerfaces. 2013;107:27-34. Available from: https://doi.org/10.1016/j.colsurfb.2013.01.061

112. Rahul S, Chandrashekhar P, Hemant B, et al. In vitro antiparasitic activity of microbial pigments and their combination with phytosynthesized metal nanoparticles. Parasitol Int. 2015;64(5):353-356. Available from: https://doi.org/10.1016/j.parint.2015.05.004

113. Adeyemi OS, Whiteley CG. Interaction of metal nanoparticles with recombinant arginine kinase from Trypanosoma brucei: thermodynamic and spectrofluorimetric evaluation. Biochim Biophys Acta. 2014;1840(1):701-706. Available from: https://doi.org/10.1016/j. bbagen.2013.10.038 
114. Adeyemi OS, Molefe NI, Awakan OJ, et al. Metal nanoparticles restrict the growth of protozoan parasites. Artif Cells Nanomed Biotechnol. 2018; Available from: https://doi.org/10.1080/21691401.2018.1489267

115. Prajapati VK, Awasthi K, Gautam S, et al. Targeted killing of Leishmania donovani in vivo and in vitro with amphotericin $B$ attached to functionalized carbon nanotubes. J Antimicrob Chemother. 2011;66(4):874-879. Available from: https://doi.org/10.1093/jac/dkr002

116. Saudagar P, Dubey VK. Carbon nanotube based betulin formulation shows better efficacy against Leishmania parasite. Parasitol Int. 2014;63(6):772776. Available from: https://doi.org/10.1016/j.parint.2014.07.008

117. Prajapati VK, Awasthi K, Yadav TP, Rai M, Srivastava ON, Sundar S. An oral formulation of amphotericin $B$ attached to functionalized carbon nanotubes is an effective treatment for experimental visceral leishmaniasis. J Infect Dis. 2012;205(2):333-336. Available from: https:// doi.org/10.1093/infdis/jir735

118. Pruthi J, Mehra NK, Jain NK. Macrophages targeting of amphotericin B through mannosylated multiwalled carbon nanotubes. J Drug Target. 2012;20(7):593-604. Available from: https://doi. org/10.3109/1061186X.2012.697168

119. Zelada-Guillén GA, Tweed-Kent A, Niemann M, Göringer HU, Riu J, Rius FX. Ultrasensitive and real-time detection of proteins in blood using a potentiometric carbon-nanotube aptasensor. Biosens Bioelectron. 2013;41:366-371. Available from: https://doi.org/10.1016/j. bios.2012.08.055

120. Costa PM, Wang JTW, Morfin JF, et al. Functionalised carbon nanotubes enhance brain delivery of amyloid-targeting Pittsburgh Compound B (PiB)-derived ligands. Nanotheranostics. 2018;2(2):168-183. Available from: https://doi.org/10.7150/ntno.23125

121. Kealey A, Smith R. Neglected tropical diseases: infection, modeling, and control. J Health Care Poor Underserved. 2010;21(1):53-69. Available from: https://doi.org/10.1353/hpu.0.0270

122. Liu $Q$, Zhou $X N$. Preventing the transmission of American trypanosomiasis and its spread into non-endemic countries. Infect Dis Poverty. 2015;4(1):60. Available from: https://doi.org/10.1186/ s40249-015-0092-7

123. Kalimuthu K, Lubin BC, Bazylevich A, et al. Gold nanoparticles stabilize peptide-drug-conjugates for sustained targeted drug delivery to cancer cells. J Nanobiotechnology. 2018;16(1):34. Available from: https://doi. org/10.1186/s12951-018-0362-1

124. Shen Y, Cao B, Snyder NR, Woeppel KM, Eles JR, Cui XT. ROS responsive resveratrol delivery from LDLR peptide conjugated PLA-coated mesoporous silica nanoparticles across the blood-brain barrier. J Nanobiotechnology. 2018;16(1):13. Available from: https:// doi.org/10.1186/s12951-018-0340-7

125. Kyriazi ME, Giust D, El-Sagheer AH, et al. Multiplexed mRNA sensing and combinatorial-targeted drug delivery using DNA-gold nanoparticle dimers. ACS Nano. 2018;12(4):3333-3340. Available from: https://doi. org/10.1021/acsnano.7b08620

126. Zhong Y, Zeberl BJ, Wang X, Luo J. Combinatorial approaches in postpolymerization modification for rational development of therapeutic delivery systems. Acta Biomater. 2018;73:21-37. Available from: https:// doi.org/10.1016/j.actbio.2018.04.010

127. Zhang C, Zhang S, Zhi D, Cui J. Cancer treatment with liposomes based drugs and genes co-delivery systems. Curr Med Chem. 2018;25(28):33193332. Available from: https://doi.org/10.2174/092986732566618011 1093937

128. Allahyari M, Mohit E. Peptide/protein vaccine delivery system based on PLGA particles. Hum Vaccin Immunother. 2016;12(3):806-828. Available from: https://doi.org/10.1080/21645515.2015.1102804

129. Firouzmand $H$, Sahranavard $M$, Badiee A, et al. The role of LPDnanoparticles containing recombinant major surface glycoprotein of Leishmania (rgp63) in protection against leishmaniasis in murine model. Immunopharmacol Immunotoxicol. 2018;40(1):72-82. Available from: https://doi.org/10.1080/08923973.2017.1407941

130. Eskandari F, Talesh GA, Parooie M, et al. Immunoliposomes containing Soluble Leishmania Antigens (SLA) as a novel antigen delivery system in murine model of leishmaniasis. Exp Parasitol. 2014;146:78-86. Available from: https://doi.org/10.1016/j.exppara.2014.08.016

131. Zhang YR, Lin R, Li HJ, He WL, Du JZ, Wang J. Strategies to improve tumor penetration of nanomedicines through nanoparticle design. Wiley Interdiscip Rev Nanomed Nanobiotechnol. 2018;11(1):e1519.

132. Zhang M, Kim JA, Huang AY. Optimizing tumor microenvironment for cancer immunotherapy: beta-glucan-based nanoparticles. Front Immunol. 2018;9:341. Available from: https://doi.org/10.3389/fimmu.2018.00341 